Article

\title{
An Improved Intellectual Capital Management Method for Selecting and Prioritizing Intangible-Related Aspects: A Case Study of Small Enterprise in Thailand
}

\author{
Ratapol Wudhikarn 1,2 (D) and Danaitun Pongpatcharatorntep 1,2,3,* \\ 1 Knowledge and Innovation Management, College of Arts, Media and Technology, Chiang Mai University, \\ Chiang Mai 50200, Thailand; ratapol.w@cmu.ac.th \\ 2 A Research Group of Modern Management and Information Technology, \\ College of Arts, Media and Technology, Chiang Mai University, Chiang Mai 50200, Thailand \\ 3 China Intelligence Center, College of Arts, Media and Technology, Chiang Mai University, \\ Chiang Mai 50200, Thailand \\ * Correspondence: danaitun.p@cmu.ac.th
}

check for

updates

Citation: Wudhikarn, R.

Pongpatcharatorntep, D. An

Improved Intellectual Capital

Management Method for Selecting and Prioritizing Intangible-Related Aspects: A Case Study of Small Enterprise in Thailand. Mathematics 2022, 10, 626. https://doi.org/ $10.3390 /$ math10040626

Academic Editors: James Liou and Artūras Kaklauskas

Received: 22 December 2021

Accepted: 16 February 2022

Published: 17 February 2022

Publisher's Note: MDPI stays neutral with regard to jurisdictional claims in published maps and institutional affiliations.

Copyright: (C) 2022 by the authors. Licensee MDPI, Basel, Switzerland. This article is an open access article distributed under the terms and conditions of the Creative Commons Attribution (CC BY) license (https:// creativecommons.org/licenses/by/ $4.0 /)$

\begin{abstract}
This study develops a new integrated approach for improving deficiencies relating to executives' intuitive or illogical decisions, mainly found in past intellectual capital management (ICM) methods. To simultaneously rectify several flaws, the process model of intellectual capital (IC), a traditional ICM method, is integrated using decision science methods-the analytic network process (ANP) and quality function deployment (QFD). The process model of IC is adopted as a core procedure of the proposed ICM approach. ANP is integrated to improve the ability to consider relationships among the IC critical factors and their impacts, while QFD is included to facilitate the systematic consideration and identification of correlations, linkages, and impacts between all IC-related elements from the business concept to strategic plans. The proposed method was applied to two case studies in one real enterprise in Thailand. The results of the implementation reveal the priorities of all IC-related aspects, and the first priority of key success factors (KSFs), key performance indicators (KPIs), and action plans (APs) are all associated with the organization in the structural capital dimension. The results demonstrate that the method may offer advantages with respect to the conceptual expectations and may prioritize critical IC factors and identify their weights. Furthermore, the improved method could indicate the correlations and impacts between related elements, such as critical factors and associated indicators. This study proposes a new comprehensive and systematic management framework by integrating different concepts-decision science methods and the ICM method. To the best of the authors' knowledge, this improved approach has not been explored or proposed in earlier studies.
\end{abstract}

Keywords: intellectual capital management; multi-criteria decision making; the process model; analytic network process; quality function deployment

\section{Introduction}

Fierce competition in today's business world has compelled most organizations to continuously adapt and improve themselves to keep pace with their competitors and to ensure their sustainable survival in the market. Intellectual capital (IC) is among the critical factors that may significantly and sustainably benefit organizations [1]. Over the last two decades, several studies and real-life implications have demonstrated that good IC management (ICM) can significantly benefit organizations in many aspects. Several IC studies have been proposed, and these can typically be categorized into four types: (1) categorization and framework of IC, (2) IC measurement and impact of IC on business performance, (3) practical use and management of IC, and (4) development of ICM method. Among these various groups of studies, the measurement of IC performance and its impact 
on business performance was found to have received the most attention [2]. Although studies of this nature may clarify and emphasize IC's relationships with and benefits for organizations, they have primarily drawn attention to IC's importance. Nevertheless, the focus on IC's measurement and impact is no longer sufficient nowadays: ICM has also been identified as a critical aspect of organizational success. Therefore, to ensure organizations ${ }^{\prime}$ prosperity and sustainability, ICM methods and theories must be developed [3].

Regarding the importance and advantages of IC, many ICM methods have been proposed in recent decades, including the Skandia value scheme and Skandia navigator [4], balanced scorecard or BSC [5], thinking and non-thinking assets [6], the process model of IC [6], intangible asset monitor [7], national intellectual capital index [8], a new IC model [9], and the Value Explorer [10]. Although most of the proposed IC methods were claimed as management approaches, they still mainly either define types as well as the amount of intangible assets or evaluate IC performance to monetary units. The limited methods include BSC, the process model of IC, and the integrated ICM approach, which provide comprehensive processes for managing IC from the business concept to strategic planning as well as performance measurement. Although these proposed methods could offer beneficial frameworks for managing and measuring organizations' intangible assets, they still have some fundamental deficiencies that prevent the proper facilitation of ICM, including (1) the incompetence in identifying relational impacts among IC-related elements, (2) the inability to prioritize IC-related aspects, and (3) a lack of trade-off consideration regarding IC-related elements.

As a result of these flaws, the established ICM approach in organizations using traditional methods still fails to consider several critical managerial aspects, and these weaknesses could lead to critical damage to organizational performance [11]. Several studies in recent decades have proposed improved frameworks aimed at resolving the abovementioned issues. Nevertheless, most of the improvements address only one deficiency of the traditional ICM methods [12-14]. An in-depth literature review reveals few attempts [15-17] to solve more than one of the above-mentioned issues simultaneously.

Although several of the proposed approaches promise new advantages and have the potential to address the traditional ICM methods' critical flaws, the processes and results of the improved approaches still fall short of ICM's strategic activities or action plans. Moreover, these developed methods applied the specific IC concept incorrectly, providing rough dimensions of IC. This rough concentration is inconsistent with the current competitive situation, which requires a focus on a wide range of IC that could cover all aspects of IC elements [18,19]. As previously mentioned, despite the availability of approaches that could solve several of the traditional ICM methods' flaws, none of these improved approaches can simultaneously resolve all critical deficiencies of past ICM methods. Therefore, current methods are still unable to comprehensively and appropriately identify and construct the ICM approach, and this could directly and negatively affect organizations' competitiveness.

Therefore, in light of the aforementioned gap and scope for improvement, this study aims to propose a new hybrid method to simultaneously address all fundamental deficiencies of the traditional ICM approach and its other subsequently improved forms mentioned above. This research intends to develop a systematic ICM framework that could identify and link all related managerial components, appropriately extract the comprehensive range of IC elements, prioritize the practical and logical measures, and consider IC's trade-off characteristics altogether. Furthermore, to determine the limitations of this improved method, the proposed approach is further applied to two real business units, which are food production and non-organic farming of the Thai Healthy Hub Company (THHC). This company is a small enterprise in Thailand, a developing country.

This paper is organized as follows: Section 2 provides a review of the literature relating to ICM methods and their improvements. Section 3 develops and describes a framework for the proposed method. Section 4 exemplifies the improved ICM method implemented in 
a case study and its results. Section 5 discusses the method's strengths and weaknesses. Finally, Section 6 concludes the paper and suggests possible opportunities for improvement.

\section{Literature Reviews}

To provide a comprehensive theoretical background as well as the development, advancement, and gaps of earlier studies, this section is broadly divided into two parts. The first subsection focuses on the traditional ICM methods and particularly their deficiencies, while the second subsection mainly reviews studies relating to the solutions and improvements of past ICM methods.

\subsection{ICM Methods}

Regarding IC's empirical advantages, many scholars have proposed various ICM methods in recent years, with the Skandia value scheme, BSC, thinking and non-thinking assets, the process model of IC, the intangible asset monitor, and the national intellectual capital index among the best known. Nevertheless, most proposed methods still consider only partial aspects of ICM, particularly the classification, determination, measurement, and evaluation of IC [3]. For example, the Skandia value scheme [4] classified IC into two major components—human capital and structural capital—and the major component of structural capital is further subdivided into two subdimensions. All classifications and relationships are presented in a hierarchical structure. The intangible asset monitor [7] is a measurement method that specifically assesses an organization's intangible performance. Using this method, IC indicators pertaining to the company's strategy are identified and then classified into three major components: external structure, internal structure, and competence. The national intellectual capital index [8], another well-known ICM method, is an evaluation method used to assess a nation's IC. The method classifies national IC into five categories: financial capital, human capital, process capital, renewal capital, and market capital. Like the examples presented above, most methods still focus on certain aspects of the management process. This partial approach cannot identify a clear process for comprehensively managing IC, and the executives implementing these methods still mainly rely on their experience and intuition [17]. The dependence on past methods and experience fails to adequately support organizations and managers to manage IC, and this negatively affects companies' competitiveness and sustainability.

A limited number of methods-BSC [5], the process model of IC [6], and the integrated approach of ICM [3] — provide a comprehensive and systematic framework to manage IC from business concept/core competency until performance evaluation. Although these three proposed approaches can cover more managerial processes and aspects of IC than other methods, they still have some similar basic deficiencies that prevent them from properly facilitating ICMs, including (1) their inability to systematically and logically identify relationships and impacts between IC-related elements, such as key performance indicators (KPIs) and related key success factors (KSFs), between KPIs and coherent strategic action plans $[12,17,20]$, and associated strategic activities or action plans; (2) their inability to prioritize IC, KPIs, and action plans [21,22]; and (3) their inability to consider characteristics of relationships or trade-offs among all considered IC elements [23]. All three ICM methods have all the above-mentioned issues, although some can partially handle some deficiencies. The methods' deficiencies are summarized in Table 1 and explained in detail below.

Of the three well-constructed IC methods mentioned above, BSC is the least defective since it can partially address some of the above critical deficiencies. BSC is a well-known IC and strategic management method that provides a systematic process to transform a company's ultimate goal into coherent practical actions for managing IC, and this can create linkages between IC-related factors at many levels, such as between objectives and KPIs, between KPIs and action plans, etc. Nevertheless, as Table 1 illustrates, the method cannot completely address the ICM method's first fundamental issue, as it is unable to consider impacts between related aspects of IC [24]. Similar to the third deficiency, BSC can partially handle this issue by indicating a trade-off among IC elements because it can 
consider only the relationships among strategic objectives. Nevertheless, similar to other well-constructed IC methods, BSC has no procedure that allows it to prioritize IC and its related elements [25].

Table 1. Deficiencies of ICM methods.

\begin{tabular}{|c|c|c|c|}
\hline \multirow[t]{2}{*}{ Well-Constructed ICM Methods } & \multicolumn{3}{|c|}{$\begin{array}{l}\text { Basis Deficiencies of Methods } \\
\text { (Mentioned Paragraph Above) }\end{array}$} \\
\hline & 1st Issue & 2nd Issue & 3rd Issue \\
\hline BSC & $\theta$ & $\mathbf{x}$ & $\theta$ \\
\hline The process model of IC & $\theta$ & $x$ & $x$ \\
\hline The integrated approach of ICM & $\mathbf{x}$ & $\mathbf{x}$ & $\mathbf{x}$ \\
\hline
\end{tabular}

Remark: $Q$-partial problem; $\mathbf{X}$-complete problem.

The process model of IC is another ICM method that provides a systematic framework for managing intangible assets from the business concept to IC performance measurement and classification. The process model of IC is specifically constructed for ICM purposes, unlike BSC, which was essentially created for strategic management. However, the process model resembles BSC in many aspects, particularly with respect to its methodological deficiencies. The process model of IC may provide a logical and systematic process for ICM, but it cannot evaluate the magnitudes of considered IC elements $[6,17]-$ KSFs and KPIs. Moreover, as Table 1 demonstrates, this method cannot prioritize or identify ICrelated elements.

The newest ICM method is the integrated approach, which provides a comprehensive framework by converting a strategy of the organization to IC and resources investment and their related performance evaluations. Nevertheless, this method mainly provides a general management framework that cannot adequately identify details of the ICM process. Moreover, since its recent presentation, no research has implemented this method to manage IC in organizations, so evidence of its advantages over other ICM methods is lacking. Furthermore, based on the proposed methodology providing only rough ICM steps, this method could not address all critical deficiencies of the ICM method as depicted in Table 1, and thus it is insufficient to support management in identifying relationships, impacts, and priorities of IC elements.

As noted above with respect to the first and second deficiencies of IC methods, all wellconstructed methods are still unable to properly enable executives to logically prioritize ICM elements (e.g., KSFs, KPIs, strategic objectives, managerial plans) and to systematically consider the impacts of relationships between considered IC aspects and their associated parts. Therefore, a lack of awareness regarding these aspects could negatively affect the executives' decisions, particularly when organizations have excessive requirements and the available resources are limited. Moreover, in the absence of a clear and specific methodological process, these deficiencies cause executives to make intuitive and formless decisions, and the obtained priorities would be illogical and irreplicable, particularly decisions made by inexperienced decision makers.

The lack of capability to identify and consider relationships as well as trade-offs among IC is the last critical deficiency found in all ICM methods except BSC because BSC could partially handle this issue. The relationships and trade-offs among intangible assets and among their related aspects are fundamental characteristics of IC. Therefore, the methods' inability to consider these characteristics may not support executives in managing IC accurately [11,17]. Regarding this weakness, the highly important IC elements that positively influence other capitals may not be consolidated and managed. Therefore, budgets and resources would be mainly allocated for managing less important IC, and this may not directly affect organizations' business goals [25].

As noted above, although some well-constructed ICM methods exist, they still have several limitations, which could lead to inappropriate decisions and management. Improper IC management can cause damage to both the employee and the organization, both 
of which are intangible assets, and, finally, it critically affects the organization's competitive advantages and sustainability. Despite limited attempts to address the issues mentioned above, no approaches that could improve all these deficiencies simultaneously have yet been proposed.

\subsection{Improving ICM Methods}

To address the critical weaknesses of the ICM methods presented above, several researchers have proposed improved approaches that may be classified into two major categories. The first main group aims to solve only one specific deficiency of ICM methods. The studies in this category can be further subdivided into two subgroups. The first subgroup aims to solve the first weakness of ICM methods, whereas the second subcategory concentrates specifically on improving the second issue of ICM methods.

For the first subcategory, most studies [12,26] have tried to solve the issue of the inability to identify the relationships and impacts between IC-related elements by integrating quality function deployment or QFD [27] with one specific ICM method-BSC. Originally, QFD was an engineering tool that created linkages as well as impacts between product-related aspects in various stages. QFD is widely used in several domains since this systematic method offers various advantages to organizations, most notably the enhancement of competitive advantages [28]. Moreover, the integration of QFD and BSC could also support firms in understanding how they can systematically manage business goals [15]. This integration of QFD with BSC could improve the systematic linkage between strategic goals and managerial processes by considering their relational impacts concurrently. Therefore, the proposed methods may provide a strong logical relationship between top managerial objectives and coherent operational elements. While this hybrid approach could improve a specific deficiency of ICM methods, it still focuses on rough IC dimensions following the BSC concept. Moreover, this proposed method still fails to address other remaining basic deficiencies. Therefore, the existing inability to examine the priorities and trade-offs or relationships among IC-related aspects still leads to managerial difficulty, particularly in identifying and screening critical IC elements [29] when top managers confront multiple complex IC elements, such as KPIs, KSFs, and so on. This flaw could ultimately result in critical losses to organizational performance [11].

The studies classified in the second subgroup aim specifically to resolve the method's second weakness, which is the issue of prioritization. There are various studies in this group proposing the integration of multi-criteria decision-making (MCDM) methods with IC methods since it has been identified as the solution for a similar problem in other fields. From various studies, the most commonly applied MCDM method for improving IC methods is the analytic hierarchy process (AHP). The AHP method and its adapted form were broadly used to identify weights and to rank IC-related elements at the same time [13,14,22,29,30]. Nevertheless, most of the proposed and improved approaches were developed in accordance with the rough IC dimension classifications following the traditional IC and BSC concepts. This rough classification causes executives to only superficially examine or neglect some aspects and elements of IC, which could also bring competitive advantages to organizations. Therefore, to improve this issue, one study applied the concepts of thinking and non-thinking IC with AHP. The integration of these methods can better assist management in comprehensively considering more crucial elements as well as details of IC and, moreover, prioritizing these intangible assets [22]. Although all improved approaches in this subcategory could address one of the fundamental weaknesses of the ICM methods, like the first subgroup, these methods continue to overlook other basic deficiencies.

Failure to address many of the ICM method's deficiencies could exert several substantially negative impacts on organizations, as mentioned in the previous section. Therefore, to promote better ICM than the methods in the first major category, the second group of studies aims to simultaneously address multiple basic weaknesses. The studies in this category are limited, but they may still be categorized into two subgroups. The first sub- 
group addresses the second and third issues of ICM methods altogether. To prioritize IC aspects and account for their relationships, some scholars applied the analytic network process or ANP [31], which is an improved form of AHP and considers interdependence among several focused elements. Regarding this crucial ability, the ANP was integrated with the ICM approaches to address the deficiencies of formerly proposed methods in the first main group of research. Numerous recent attempts have sought to improve the ICM approach with the ANP, and almost all studies have integrated ANP with the BSC $[14,32,33]$. Nevertheless, owing to the rough IC dimensions of BSC, this integrated method is still ineffective in assisting the comprehensive consideration of multidimensional elements and details of IC. One recent study [17] proposed the integration of thinking and non-thinking IC concepts [6] with ANP, and this approach could appropriately and comprehensively consider more IC dimensions than the BSC-ANP approach. Although the studies in this subcategory could improve another specific issue relating to prioritization in ICM, these proposed methods still fail to consider the systematic process used to extract IC-related elements and their relational impacts (the first weakness of ICM methods). Moreover, these improved forms still only concentrate on the rough IC dimensions, leading to limited management capability.

In light of this limitation, another subcategory of studies has aimed to improve another set of two deficiencies-the first and second issues. The more complicated integrations of MCDM methods, the QFD technique, and a specific ICM method (BSC) were recently suggested in a few studies. In recent years, Murali and Pugazhendhi [34] proposed an integrated model combining BSC, QFD, and AHP, and at nearly the same time, Hsu and his colleagues [35] suggested a hybrid method combining BSC, QFD, and techniques for order preference by similarity to an ideal solution (TOPSIS). These integrated models could simultaneously address the first and second weaknesses of ICM methods. These improved approaches could reveal further details about relational impacts among ICrelated aspects and are also able to prioritize critical IC-related elements. However, the proposed methods adopt the BSC method, which is still limited by its consideration of three rough major elements of IC, and moreover, these approaches continue to neglect the trade-off characteristic of ICM. Therefore, this category of proposed methods continues to provide only rough perspectives on ICM, limiting the comprehensive consideration and management of executives. Moreover, the failure to consider trade-offs leads to the omission of significant influenceable IC-related aspects.

Although the improved approaches in two subgroups of the major second category are able to solve more than one deficiency of the ICM method, they are still unable to resolve all critical constraints of ICM methods simultaneously. Nevertheless, the intensive review reveals that studies $[15,16]$ that can address all deficiencies of ICM methods are limited. These studies integrate QFD, BSC, and ANP in combination. The integration of ANP is better than AHP and several MCDM methods at improving QFD since it considers elements of a problem as a dependency network, which is mostly related to real-life problems. Moreover, the integration of QFD and ANP is better able to handle multidimensional, complex, and interdependency aspects and criteria, which are fundamental characteristics of ICM. The combination of these two methods may also be beneficially applied under various research settings [36], including the ICM [15,16]. Regarding distinctive advantages of QFD and ANP, this integrated approach should be able to address all deficiencies or should provide a systematic framework for managing IC by simultaneously identifying relational impacts of IC-related elements, prioritizing IC-considered aspects, and considering ICM's trade-off characteristics. However, these studies still have several drawbacks that warrant further improvement. These studies applied BSC as a core concept, and so the fundamental weakness of BSC that roughly considers IC elements remains. Moreover, these proposed methods provide a limited scope of framework for managing IC aspects. Although the studies could prioritize and quantify relational impacts of IC aspects, which are strategic objectives, they remain unable to provide a comprehensive framework that can address ICM methods' basic deficiencies from strategic concepts to tactical or operational actions. 
Moreover, one of the studies [16] only proposed a conceptual, methodological framework without a case study. Hitherto, the realization of complex integration, which combines more than three methods, has been exceptional, and further investigations are required.

As mentioned above, several studies have sought to improve ICM methods' deficiencies, but most only partially addressed the methods' weaknesses. Until now, no integrated method capable of completely solving all the basic weaknesses of the traditional ICM method simultaneously has been proposed. Although few studies have proposed improved approaches that could simultaneously address most basic deficiencies of IC traditional methods as well as their improved forms, some critical disadvantages of these methods-the limited scope of management framework and the rough consideration of IC elements-remain. Therefore, regarding the importance of the above-mentioned issues and the existing improvement opportunities, this study proposes an improved method by optimizing the integration of several appropriate methods to simultaneously address the three basic weaknesses of traditional ICM methods and issues emerging from other improved ICM approaches. The proposed integration approach is explained in the methodology section.

\section{Research Methodology}

The intensive literature review presented in the previous section highlights several potential methods that can be further improved and extended to resolve all existing issues. As observed above, the integration of BSC, QFD, and ANP represents the most appropriate approach; however, it cannot solve all fundamental deficiencies of ICM methods simultaneously. In addition to the remaining deficiencies, the method also has its own weaknesses. Therefore, to improve all existing issues, this study proposes the novel integration of the process model of IC, thinking and non-thinking assets, QFD, and ANP. To improve on BSC's weakness to be able to systematically and logically manage IC, the process model of IC [6] is applied as a core method for ICM from the business concept to performance measurement. The method is applied for identifying ICM aspects, including a business concept, KSFs, and associated KPIs. In addition to this core method, the thinking and non-thinking assets concept [6] is adopted to support the identification and categorization of IC since this method can provide more IC details and dimensions than the rough concept of BSC or other IC concepts. The thinking and non-thinking IC concept comprehensively considers two major components of IC—human capital and structural capital—and each component consists of three IC dimensions. Competence, attitude, and intellectual agility are subdimensions of human capital, while relationships, organization, and renewal and development are subdimensions of structural capital [6]. These particular dimensions of IC have also been mentioned and proposed by several widely cited articles [37,38]. Therefore, by integrating this comprehensive IC concept into the proposed method, it may support the extensive consideration of IC from the three broad IC perspectives (e.g., BSC, traditional IC concepts) to six comprehensive dimensions.

To improve the first basic weakness of the method, QFD [27] is integrated into the process model of IC. It is applied to identify linkages and impacts between both KSFs and KPIs as well as between KPIs and action plans. This extended scope of QFD integration, until the strategic actions are obtained, is proposed to improve the limitations of the scope of past works. Finally, to address the second and third deficiencies of ICM methods, ANP [31] is integrated into the QFD to identify and consider trade-offs among IC-related aspects and to prioritize their importance. The overall framework can be concluded as shown in Figure 1.

As Figure 1 illustrates, the proposed method can be divided into four major steps, and the details of each stage are described as follows: 


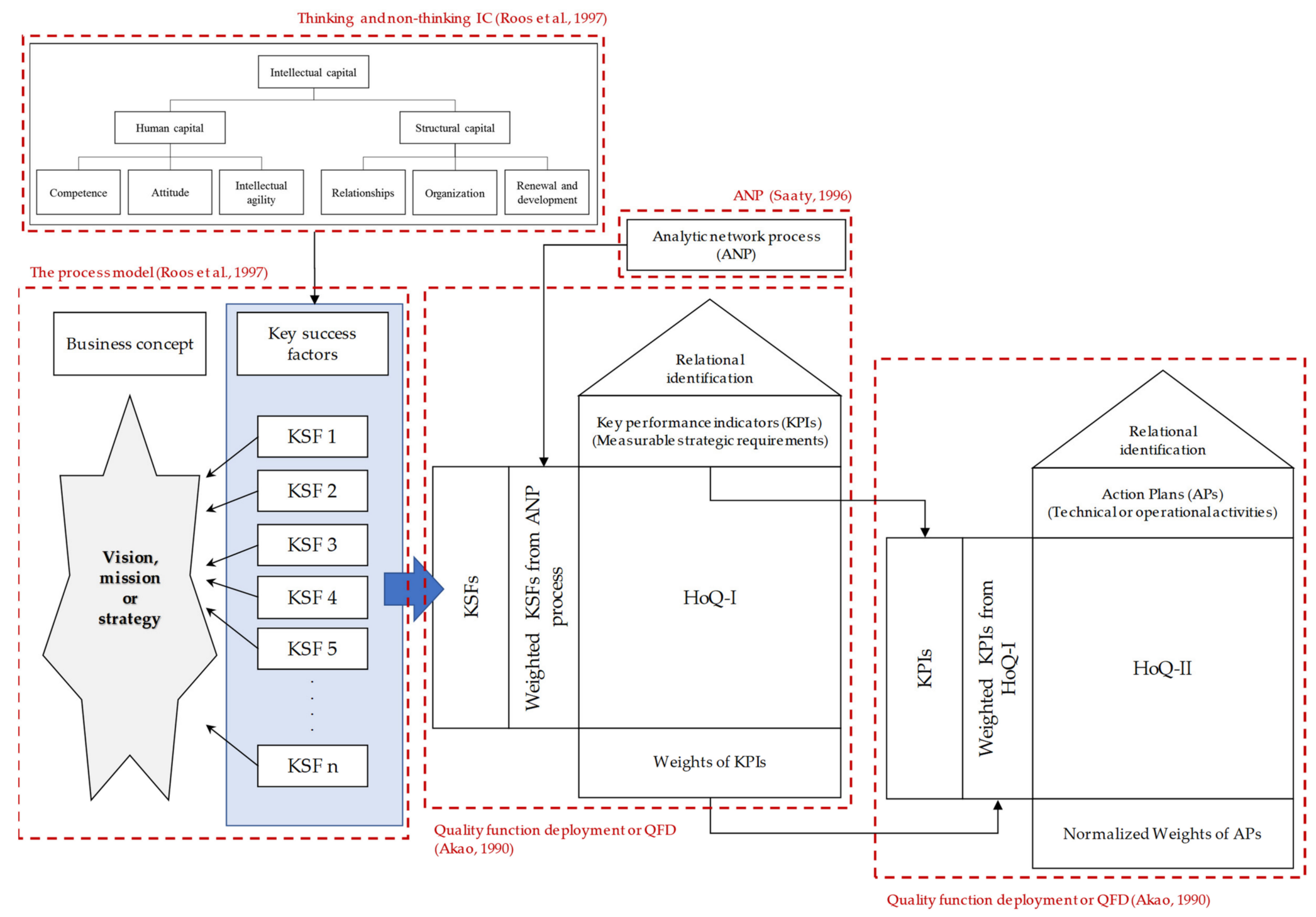

Figure 1. A research framework. 
Stage 1: Establishing business concepts and KSFs of organization

The first step aims to identify a business concept, the key components of corporate strategy, and factors critically affecting the organization's long-term goals. Following the original process of the process model of IC, an executive of the organization is interviewed using an open-ended questionnaire (1st-round inquiry) to establish or identify the organization's vision, mission, strategy, and KSFs. Regarding the applied ICM concept, KSFs represent the critical IC factors that significantly influence the achievement of corporate strategy and the ultimate goals of organizations. Thus, the results from the traditional process still cannot provide the necessary data regarding the significance or priority of KSFs as well as the influences between KSFs and the relational impacts between KSFs and other coherent parts. Therefore, to improve this issue, QFD and ANP are integrated with the core IC concept in the next step.

Stage 2: Identifying the relationships and impacts of KSFs and KPIs

The second major step focuses on the identification of KPIs and the associations between KPIs and KSFs, as well as their relational impacts. To identify both the relationships and impacts of all IC-related elements, QFD and ANP are integrated into the process model of IC. QFD is another main method that is integrated to support the identification of relationships between KSFs and KPIs, as well as their relational impacts. In the proposed model, ANP is also integrated into QFD to identify priorities and KSFs' importance ratings or weights. Therefore, following the ANP procedure, the structured questionnaire (2ndround inquiry) is sent to the participating expert to indicate the relationships among related KSFs. According to the ANP network model, the relationship between two KSFs may be identified as one of three types: (1) no relationship between the two; (2) a one-way relationship indicating that only one KSF affects the other; and (3) a two-way relationship indicating that the two KSFs influence one another. In this inquiry, the expert must consider the relationships between one KSF and the others on a one-by-one basis. Subsequently, the identified associations among the KSFs are used to design a new questionnaire (3rd-round inquiry) for further use. The 3rd-round inquiry asks the expert to compare all related KSFs in a pairwise manner following the 1-9 ANP scale [31].

Therefore, the results of the comparisons are applied to construct a supermatrix, which may be shown as a matrix (1) and then applied to calculate the KSFs' weights and priorities in accordance with the ANP concept. In this step, the consistency ratio (CR) of the obtained results is calculated using Equation (2).

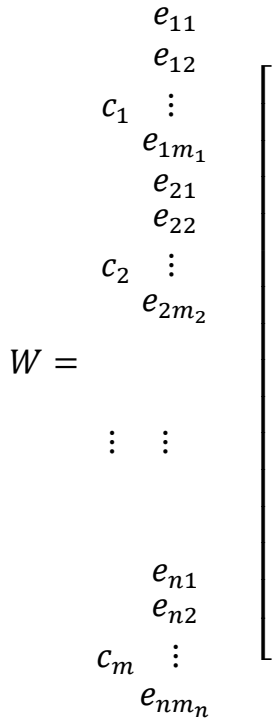

$W_{11}$
$W_{21}$
$W_{n 1}$

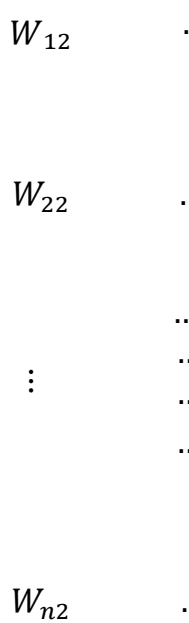

$\mathrm{CR}=\mathrm{CI} / \mathrm{RI}$ 
where $\mathrm{CI}$ is the consistency index, which can be calculated using Equation (3).

$$
\mathrm{CI}=\frac{\lambda_{\max }-n}{n-1}
$$

where, $\lambda_{\max }$ is the maximum eigenvalue and $n$ is the number of attributes.

From Equation (2), RI is the random consistency index, which is applied to measure the degree of inconsistency of the matrix (1). Its value depends directly on the number of attributes denoted by $n$, and using Saaty's test, RI can be obtained from Saaty's book [31].

For the CR calculation following Equation (2), the obtained CR result must conform to an acceptable level (lower than 10\%); otherwise, the inquiries must be repeated until the results meet the specified level (if any). However, the ANP procedures presented above are only brief details of the major steps. Further explanations and details of both ANP [31,39] and QFD [27], applied in the next process, can be found in the authors previous publications.

After obtaining KSFs, the levels of relational importance among KPIs as well as between KPIs and KSFs are identified through the questionnaire (4th-round inquiry) and subsequently calculated following the QFD concept. The first house of QFD is constructed following the QFD concept as presented in Figure 2, and the main procedure is presented below.

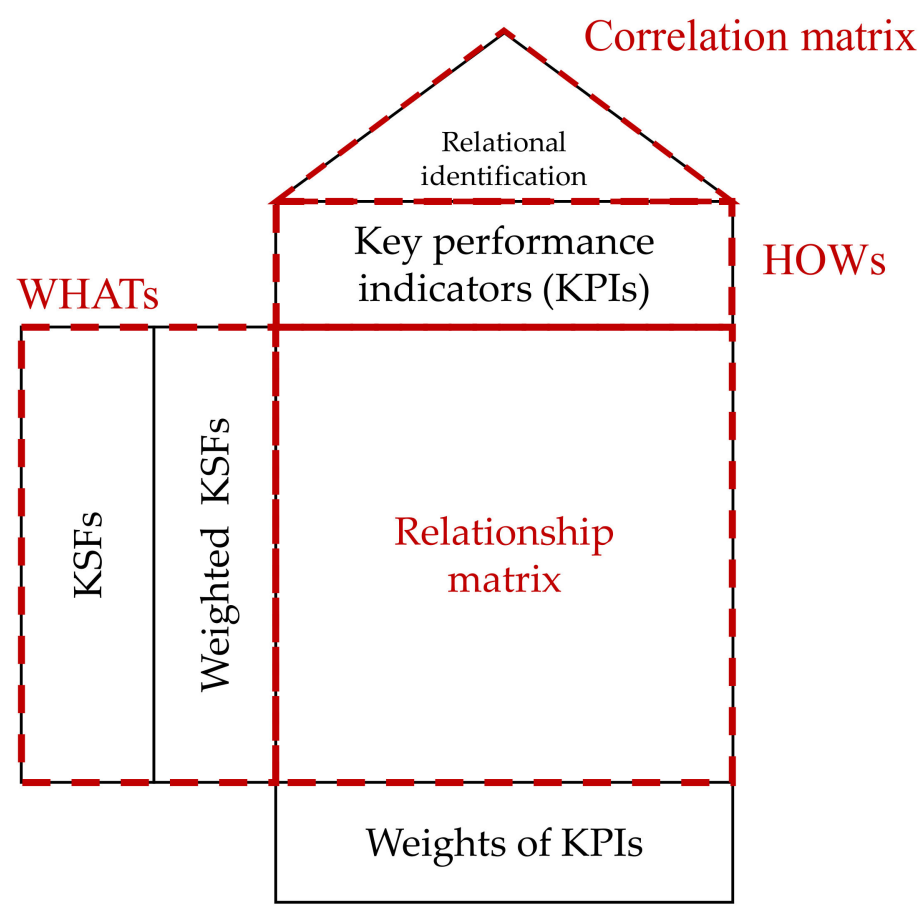

Figure 2. Structure and components of the house following the QFD concept.

(1) The previously obtained KSFs are part of "WHATs", in accordance with the first house of the QFD concept. The KSFs' weights are calculated based on the ANP method, as presented above.

(2) The "HOWs" of the house is used to identify KPIs relating to the KSFs. In this step, the levels of correlation between associated KPIs must be identified at the roof of the house (correlation matrix), and the correlation levels may be rated as strongly positive $(++)$, positive $(+)$, neutral (blank), negative $(-)$, and strongly negative $(--)$.

(3) Relationships between KSFs and KPIs are developed at the body of the house (relationship matrix). The level of relationships based on the predefined rating scales-1 (weak), 3 (medium or moderate), 9 (strong) —is assigned to each segment of the matrix. The segment without any relationship will be left blank. 
(4) At the bottom of the house, the KPIs' importance weights are calculated using Equation (4)

$$
I W_{j}=\sum_{i=1}^{m} w_{i} r_{i j}
$$

where $I W_{j}$ is an importance weight of $\mathrm{KPI} j ; j=1,2,3, \ldots, l ; w_{i}$ is the weight of $\mathrm{KSF} i$; $i=1,2,3, \ldots, m ; r_{i j}$ is the value representing the level of relationship between KSF $i$ and KPI $j$.

(5) The obtained weights are further normalized to rescale values on a scale ranging from 0 to 1 by Equation (5)

$$
\widetilde{I W}_{j}=\frac{I W_{j}}{\sum_{j=1}^{l} I W_{j}}
$$

where $\widetilde{I W}_{j}$ is the normalized important weight of $\mathrm{KPI} j ; j=1,2,3, \ldots, l$.

The results from this step are used to complete the first house of QFD. This house aims to present the importance weights of both KSFs and KPIs as well as linkages and relational impacts between them.

Stage 3: Indicating relationships and impacts of KPIs and action plans

In this phase, QFD is again applied but this time aims to identify IC-related activities or action plans significantly related to the strategic requirements in the previous step. Similar to the application in the previous step, the relationships between action plans and KPIs, as well as their important levels of the association, are identified through the questionnaire ( $5^{\text {th }}$-round inquiry). To construct the second house of QFD, KPIs are identified for the "WHATs" component, and action plans are specified for the "HOWs" component. The QFD development is similar to the procedure presented in Stage 2 above. The results from this step are used to create the second house of the QFD concept. Finally, regarding this house model, the priorities and importance weights of identified action plans that respond to the business concept and critical factors of the organization and cover a comprehensive range of IC will be obtained.

Stage 4: Concluding priorities of all IC-related aspects

All obtained results from the former steps are prioritized and concluded to demonstrate the ranks and importance of all IC-related aspects. These results can be further used to manage IC at tactical and operational levels in the future.

To examine the present study's proposed approach, the method was implemented by two business units of the Thai Healthy Hub Company (THHC), which is a company in Thailand, a developing country. THHC is a local Thai company that operates several businesses, including food production, restaurants, and organic and non-organic farming. One of these cases, a food factory, is used to exemplify the details of the implementation processes while, to better reflect the proposed method's strengths and weaknesses, feedback on the applications is obtained from both case studies.

\section{Results}

The results and details of the application in the food factory case using the proposed method's procedures are presented below.

Stage 1: Establishing business concepts and KSFs of organization

In this step, the managing director (MD) of THHC's food business was interviewed using the constructed questionnaire. This first-round inquiry aims to identify and collect the unit's business and policy concepts. All business-related concepts and KSFs of THHC's food business are presented in Table 2.

Stage 2: Identifying relationships and impacts of KSFs and KPIs

Following the proposed method's procedure, ANP was first applied to prioritize KSFs obtained from the previous step. Initially, KSFs were identified by the MD for their relationships among themselves via the questionnaire for the second-round inquiry. To 
visualize relationships among all KSFs, they were first categorized into IC dimensions based on the concept of thinking and non-thinking assets. The identified relationships are then presented in network form following the ANP concept, as shown in Figure 3. A line ending with an arrowhead demonstrates that the starting KSF affects the ending KSF, whereas a two-way arrowhead indicates that both KSFs influence one another. For instance, the line with a two-way arrowhead connecting KSF3 and KSF9 indicates that KSF3 and KSF9 influence one another, while the line beginning from KSF8 and ending with an arrowhead at KSF4 indicates that KSF8 influences KSF4.

Table 2. Business-related concepts and KSFs of the case study.

\begin{tabular}{|c|c|c|c|}
\hline Business Concepts & & Details (IC Categories) & Acronyms \\
\hline Vision & \multicolumn{2}{|r|}{ To be a leader of Thai sauce and seasoning products } & $\mathrm{V} 1$ \\
\hline \multirow{3}{*}{ Missions } & (1) & Offer finest quality products at an affordable price & M1 \\
\hline & $(2)$ & Provide unique products to customers & M2 \\
\hline & (3) & Ensure on-time delivery to every order & M3 \\
\hline \multirow{3}{*}{ Strategies } & (1) & Improve production efficiency and quality assurance system & S1 \\
\hline & (2) & Develop new products at competitive prices & $\mathrm{S} 2$ \\
\hline & (3) & Improve internal and external delivery processes & S3 \\
\hline \multirow{8}{*}{ KSFs } & & $\begin{array}{l}\text { Product diversity (organization) } \\
\text { Cleanliness (organization) }\end{array}$ & KSF1 \\
\hline & (3) & On-time delivery (organization) & $\begin{array}{l}\text { KSF2 } \\
\text { KSF3 }\end{array}$ \\
\hline & (4) & Employee competence (competence) & KSF4 \\
\hline & (5) & Equipment efficiency (organization) & KSF5 \\
\hline & (6) & High-quality product (organization) & KSF6 \\
\hline & (7) & New product or innovation (renewal and development) & KSF7 \\
\hline & (8) & Employee satisfaction (attitude) & KSF8 \\
\hline & (9) & Supplier relationships (relationships) & KSF9 \\
\hline
\end{tabular}

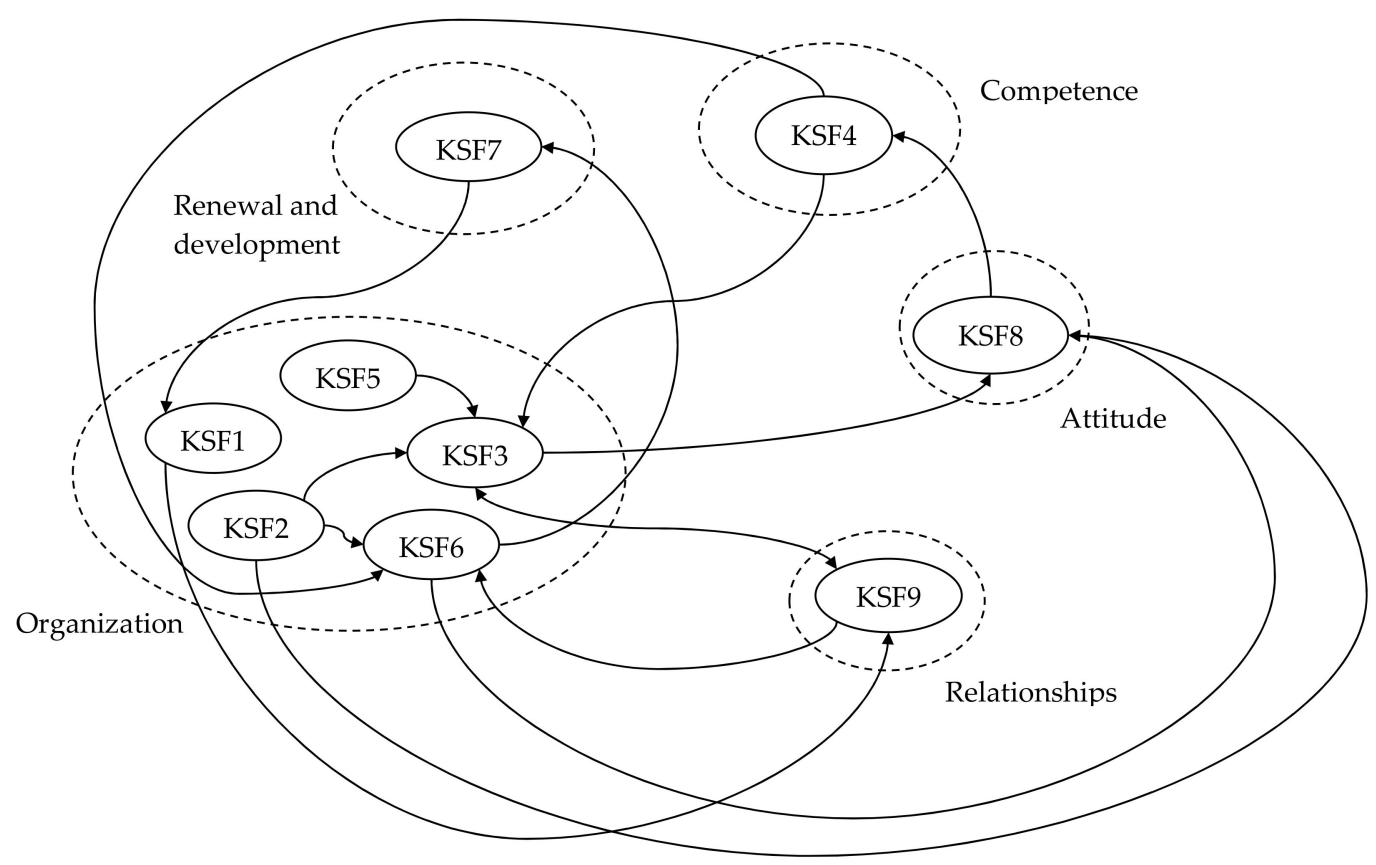

Figure 3. A network model of food factory case. 
The relationships between IC dimensions can be referred to from the KSF level: for example, the relationship between KSF8 and KSF4 implies that attitude capital influences competence capital.

These relationships were used to create the third questionnaire, designed to ask the MD to indicate the impacts of influences among related KSFs. In this study, the MD answered all provided questions, and the obtained results were inputted into the Super Decision software (version 2.10). This MCDM program calculated all required results following the ANP concept, including the unweighted supermatrix, weighted supermatrix, and limit supermatrix. Owing to this journal's word limits, only the final consistency results obtained from the limit supermatrix-KSFs' weights and priorities-are presented in Table 3. These results can be further used to calculate the weights of both IC dimensions and components, as Table 4 illustrates. Therefore, the results obtained from ANP, as shown in Tables 3 and 4, demonstrate the ranks and importance weights of IC-related aspects: the IC dimensions and KSFs of ICM. The recognition of priorities and weights in the next steps may support the executive in focusing on high-impact KSFs and other subsequences, such as KPIs and associated action plans.

In the fourth-round inquiry, the MD was asked to identify KPIs and the relational impacts or correlations among related KPIs and between KPIs and their corresponding KSFs. The identified KPIs of the focused business unit are presented in Table 5, and all results from this minor step can be concluded and depicted in a roof form, as shown in Figure 4.

Table 3. Priorities and weights of KSFs.

\begin{tabular}{ccc}
\hline Ranks & KSFs (Abbreviations) & Weights \\
\hline 1 & KSF2 & 0.434875 \\
2 & KSF6 & 0.202788 \\
3 & KSF8 & 0.080446 \\
4 & KSF7 & 0.072624 \\
5 & KSF3 & 0.068663 \\
6 & KSF4 & 0.044556 \\
7 & KSF9 & 0.044556 \\
8 & KSF1 & 0.040223 \\
9 & KSF5 & 0.011270 \\
\hline
\end{tabular}

Table 4. Priorities and weights of IC dimensions.

\begin{tabular}{lcc}
\hline \multicolumn{1}{c}{ IC Dimensions (IC Major Components) } & Weights & Ranks \\
\hline Organization (structural capital) & 0.757819 & 1 \\
Attitude (human capital) & 0.080446 & 2 \\
Renewal and development (structural capital) & 0.072624 & 3 \\
Competence (human capital) & 0.044556 & 4 \\
Relationships (structural capital) & 0.044556 & 4 \\
\hline
\end{tabular}

As Figure 4 illustrates, the roof of the first house presents the correlations between the associated KPIs of IC. The plus sign (+) represents the positive relationships between two related KPIs, while the minus sign (-) indicates the trade-off characteristic between connected KPIs. For instance, the minus sign in the grey-colored segment represents the trade-off between KPI-03 and KPI-05. Generally, when the machine downtime rate increases, it negatively affects or reduces the on-time delivery rate because the machine breakdown causes a longer operation time that, in turn, affects the delivery capability. The plus sign in the grey-colored segment represents the mutual support between KPI-08 and KPI-01. In this example, a high number of new products (KPI-08) can increase the number of products in the company's product portfolio (KPI-01).

These identified correlations were used as supporting information for considering the significance of relationships between KPIs and KSFs. The level of association between KPIs 
and KSFs was identified by the executive in the same questionnaire, and the results are presented in Figure 5.

Table 5. KPIs of the case study.

\begin{tabular}{llc}
\hline KSFs & \multicolumn{1}{c}{ KPIs } & Abbreviations \\
\hline KSF1 & No. of products in product portfolio & KPI-01 \\
KSF2 & No. of complaint cases about bad cleanliness & KPI-02 \\
KSF3 & On-time delivery rate & KPI-03 \\
KSF4 & Average training cost per employee & KPI-04 \\
KSF5 & Machine downtime rate & KPI-05 \\
KSF6 & No. of product claim cases & KPI-06 \\
KSF7 & Percentage of first-time QC pass & KPI-07 \\
KSF8 & No. of new products & KPI-08 \\
KSF9 & Employee satisfaction rate & KPI-10 \\
\hline
\end{tabular}

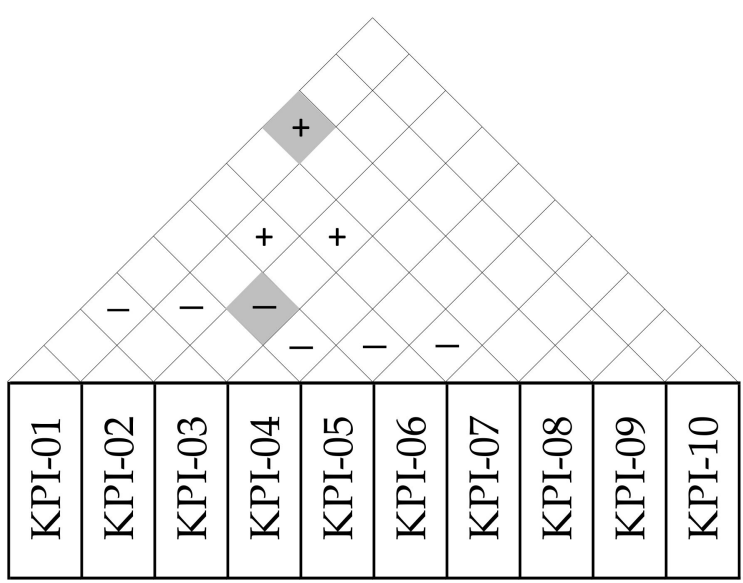

Figure 4. Correlations between KPIs of focused case.

\begin{tabular}{|c|c|c|c|c|c|c|c|c|c|c|c|}
\hline $\begin{array}{c}\text { Weights of KSFs } \\
\text { (from ANP) }\end{array}$ & KSFs / KPIs & $\frac{\bar{\sigma}}{\frac{1}{1}}$ & $\frac{\stackrel{D}{O}}{\stackrel{1}{1}}$ & 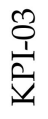 & $\begin{array}{l}\frac{J}{0} \\
\frac{1}{v} \\
\underline{v}\end{array}$ & $\frac{\underline{L}}{\underline{1}}$ & 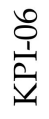 & 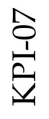 & 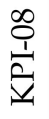 & $\frac{g}{\frac{1}{1}}$ & $\frac{0}{\frac{1}{1}} \frac{1}{\underline{V}}$ \\
\hline 0.040223 & KSF1 & 0 & & & & & & & & & \\
\hline 0.434875 & KSF2 & & 0 & & & & $\square$ & $\triangle$ & & & \\
\hline 0.068663 & KSF3 & & & 0 & & 0 & & $\square$ & & & \\
\hline 0.044556 & KSF4 & & & & 0 & & & & & & \\
\hline 0.011270 & KSF5 & & & & & 0 & & & & & \\
\hline 0.202788 & KSF6 & & $\triangle$ & & & & 0 & $\square$ & & & \\
\hline 0.072624 & KSF7 & $\square$ & & & & & & & 0 & & \\
\hline 0.080446 & KSF8 & & & & & & & & & 0 & \\
\hline 0.044556 & KSF9 & & & & & & & & & & O \\
\hline
\end{tabular}

Figure 5. Relationships and impacts between KSFs and KPIs. 
In this process, the levels of relationship between KSFs and KPIs were classified into three levels: strong $(\bigcirc)$, moderate $(\square)$, and weak $(\Delta)$. These visualized relationships and their magnitudes mainly support the executive in managing two critical managerial tasks: first, to ensure that all KSFs had corresponding KPIs; and second, to identify the critical KPIs that corresponded significantly to KSFs. The identification of the KSFs' importance in the previous step and the perceived relational impacts between KPIs and KSFs would support the identification of strategic plans and allocation of resources to significant KSFs and highly related KPIs in the next step.

The identified magnitude of relationships between KSFs and KPIs was further used to calculate the significance of KPIs following the QFD procedure. Therefore, the weights of KPIs were computed by multiplying the relational impacts of KSFs and KPIs with the KSFs' weights. Partial examples of the calculations of KPI weights are presented in Table 6.

Table 6. Partial results and calculation details of KPI weights.

\begin{tabular}{ccclc}
\hline KPIs & Associated KSFs (Weights) & Level of Relationships (Weights) & & Weights of KPIs \\
\hline \multirow{2}{*}{ KPI-01 } & KSF1 (0.040223) & $\bigcirc(9)$ & $0.040223 \times 9=0.362007$ & 0.579879 \\
& KSF7 (0.072624) & $\square(3)$ & $0.072624 \times 3=0.217872$ & 0.401004 \\
\hline KPI-04 & KSF4 (0.044556) & $\bigcirc(9)$ & $0.044556 \times 9=0.401004$ & $0.434875 \times 1=0.434875$ \\
\multirow{2}{*}{ KPI-07 } & KSF2 (0.434875) & $\Delta(1)$ & $0.068663 \times 3=0.205989$ & 1.249228 \\
& KSF3 (0.068663) & $\square(3)$ & $0.202788 \times 3=0.608364$ & \\
\hline
\end{tabular}

For example, to calculate the weight of KPI-04, the weight of KSF (KSF4; 0.044556) associated with KPI-04 is multiplied by the weight of relationships between KSF4 and KPI-04, which is 9. Finally, the calculated weight of KPI-04 is 0.401004 . If a KPI has more than one associated KSF, each multiplication between the weight of KSF and the weight of the corresponding pair's relationship must be calculated first. Subsequently, to calculate the final weight, all computed weights are combined to give the final weight of KPI. For instance, the weight of KPI-01 (0.579879) was calculated by summing two weights $(0.362007$ and 0.217872$)$ derived from the multiplication between the weight of KSF1 (0.040223) and the weight of the relationship between KPI-01 and KSF1 (9); and the multiplication between the weight of KSF7 (0.072624) and weight of relation between KPI01 and KSF7 (3).

Figure 5 and Table 5 illustrate the various relationships between KSFs and KPIs. These relationships highlight KPIs corresponding to KSFs, which could directly (strong relation) and indirectly (moderate or weak relationship) measure KSFs' performance. As presented in Figure 5, the greater the weight of KSF, the higher the numbers of KPIs assigned. This result highlights the importance of monitoring and measuring highly important KSFs. For example, the highly weighted KSFs, such as KSF2 and KSF6, had three KPIs, including strongly, moderately, and weakly related KPIs. To closely and continuously measure the performance of managerial activities, the adoption of several KPIs of critical success factors is a commonly used management strategy that has been widely identified in many studies $[40,41]$. This is to ensure that KSFs, which critically influence organizations ${ }^{\prime}$ achievement, will be instantly responded to and managed, especially when both direct and indirect organizational targets are missed.

The KPI weights obtained from the calculations were further rescaled to values ranging from 0 to 1, and finally, all results from this step were used to assemble the first house of QFD (QFD-I), as illustrated in Figure 6.

Stage 3: Indicating relationships and impacts of KPIs and action plans

Similar to the previous phase, the second house (QFD-II) was constructed again following the QFD concept. This house aims to further transform the first house's strategic concepts (KSFs and KPIs) into strategic actions. The KPIs and their weights obtained from the previous phase formed a major part of the second house. The strategic action plans (shown in Table 7), their intra-relationships (among action plans), and inter-relationships 
(between KPIs) were indicated by the MD via the 5th-round questionnaire. Similar to the first QFD, the correlations between action plans (APs) and the relationships and relational impacts between KPIs and action plans were identified at the house's roof and the body, respectively. These identifications were considered and used to calculate the APs' weights of importance as well as their priorities. All results from this step are presented in Figure 7.

\begin{tabular}{|c|c|c|c|c|c|c|c|c|c|c|c|}
\hline $\begin{array}{c}\text { Weights of KSFs } \\
\text { (from ANP) }\end{array}$ & KSFs / KPIs & KPI-01 & KPI-02 & KPI-03 & KPI-04 & KPI-05 & KPI-06 & KPI-07 & KPI-08 & KPI-09 & KPI-10 \\
\hline 0.040223 & KSF1 & O & & & & & & & & & \\
\hline 0.434875 & KSF2 & & $\mathrm{O}$ & & & & $\square$ & $\triangle$ & & & \\
\hline 0.068663 & KSF3 & & & $\mathrm{O}$ & & 0 & & $\square$ & & & \\
\hline 0.044556 & KSF4 & & & & $\mathrm{O}$ & & & & & & \\
\hline 0.011270 & KSF5 & & & & & $\mathrm{O}$ & & & & & \\
\hline 0.202788 & KSF6 & & $\triangle$ & & & & $\mathrm{O}$ & $\square$ & & & \\
\hline 0.072624 & KSF7 & $\square$ & & & & & & & $\mathrm{O}$ & & \\
\hline 0.080446 & KSF8 & & & & & & & & & $\mathrm{O}$ & \\
\hline 0.044556 & KSF9 & & & & & & & & & & $\mathrm{O}$ \\
\hline \multicolumn{2}{|c|}{ Weights of KPIs } & 0.57988 & 4.11666 & 0.61797 & 0.40100 & 0.71940 & 3.12972 & 1.24923 & 0.65362 & 0.72401 & 0.40100 \\
\hline \multicolumn{2}{|c|}{ Normalized weights of KPIs } & 0.04605 & 0.32691 & 0.04907 & 0.03184 & 0.05713 & 0.24854 & 0.09920 & 0.05191 & 0.05750 & 0.03184 \\
\hline
\end{tabular}

Figure 6. Results of the first house of QFD (QFD-I).

Table 7. Action plans of the focused company.

\begin{tabular}{cll}
\hline Action Plan (AP) Code & \multicolumn{1}{c}{ Descriptions } & \multicolumn{1}{c}{ Related KPIs } \\
\hline AP-01 & Develop new seasoning sauces & KPI-01, KPI-08 \\
AP-02 & Improve a sterilization process & KPI-02, KPI-06 \\
AP-03 & Improve a cleaning system & KPI-02, KPI-06 \\
AP-04 & Develop just-in-time production system & KPI-03 \\
AP-05 & Deal with more logistics companies \\
AP-06 & Improve production competence of staffs & KPI-04 \\
AP-07 & Develop a preventive maintenance system & KPI-05 \\
AP-08 & Purchase new equipment for quality control & KPI-06, KPI-07 \\
AP-09 & Add more quality checking processes & KPI-06, KPI-07 \\
AP-10 & Develop a customer claim system & KPI-06, KPI-07 \\
AP-11 & Improve an employee welfare system & KPI-09 \\
AP-12 & Enhance relationships with good suppliers & KPI-10 \\
\hline
\end{tabular}

The results presented in Figure 7 demonstrate that this case's first priority action plans are AP-02 and AP-03, and all APs' ranks are depicted at the lowest level of the house. These identified priorities and importance weights may be used in the future to allocate the organization's strategic budgets.

As mentioned at the beginning of this section, to better perceive the proposed method's strengths and weaknesses, it was also applied to another business unit of the THHC: the organic and non-organic farms. However, owing to word limitations and the detailed example clearly presented in the first case above, the details of the second implementation are excluded from this paper. Only the quality of the proposed method as perceived from the implementation will be considered and discussed in the next section. 


\begin{tabular}{|c|c|c|c|c|c|c|c|c|c|c|c|c|c|}
\hline $\begin{array}{l}\text { Weights of KPIs } \\
\text { (from } 1^{\text {st }} \text { house) }\end{array}$ & $\begin{array}{l}\text { KPIs / Action } \\
\text { plans (APs) }\end{array}$ & AP-01 & AP-02 & $\mathrm{AP}-03$ & $\mathrm{AP}-04$ & $\mathrm{AP}-05$ & $\mathrm{AP}-06$ & AP-07 & AP-08 & AP-09 & AP-10 & AP-11 & AP-12 \\
\hline 0.046050 & KPI-01 & $\mathrm{O}$ & & & & & & & & & & & \\
\hline 0.326914 & KPI-02 & & $\mathrm{O}$ & $\mathrm{O}$ & & & & & & & & & \\
\hline 0.049074 & KPI-03 & & & & $\mathrm{O}$ & $\square$ & & & & & & & \\
\hline 0.031845 & KPI-04 & & & & & & O & & & & & & \\
\hline 0.057129 & KPI-05 & & & & & & & O & & & & & \\
\hline 0.248538 & KPI-06 & & $\square$ & $\square$ & & & & & O & O & O & & \\
\hline 0.099204 & KPI-07 & & & & & & & & $\square$ & & & & \\
\hline 0.051905 & KPI-08 & O & & & & & & & & & & & \\
\hline 0.057496 & KPI-09 & & & & & & & & & & & $\mathrm{O}$ & \\
\hline 0.031845 & KPI-10 & & & & $\triangle$ & & & & & & & & O \\
\hline \multicolumn{2}{|c|}{ Weights of APs } & 0.88159 & 3.68784 & 3.68784 & 0.47351 & 0.14722 & 0.28660 & 0.51416 & 2.53446 & 2.23685 & 2.23685 & 0.51746 & 0.28660 \\
\hline \multicolumn{2}{|c|}{ Normalized weights of APs } & 0.05040 & 0.21084 & 0.21084 & 0.02707 & 0.00842 & 0.01639 & 0.02940 & 0.14490 & \begin{tabular}{|l|}
0.12789 \\
\end{tabular} & \begin{tabular}{|l|}
0.12789 \\
\end{tabular} & \begin{tabular}{|l|}
0.02958 \\
\end{tabular} & \begin{tabular}{|l|}
0.01639 \\
\end{tabular} \\
\hline \multicolumn{2}{|c|}{ Priorities } & 6 & 1 & 1 & 9 & 12 & 10 & 7 & 3 & 4 & 4 & 7 & 10 \\
\hline
\end{tabular}

Figure 7. Results of the second house of QFD (QFD-II).

\section{Discussions}

Nowadays, ICM is widely acknowledged as strategically important for organizations. Several ICM methods have been proposed in recent decades, but most still mainly classify IC elements into different categories and concepts. Only a limited number of ICM methods can provide a comprehensive management approach from business concept to performance measurement and strategic planning, and even these methods have some basic deficiencies, including the lack of a relationship identification process to some IC-related parts, inability to prioritize significant IC-related elements, and incapacity to demonstrate trade-off and impact between IC elements. These flaws prevented past methods from properly managing IC. To address these issues, this study has proposed an improved approach integrating three methods: ANP, QFD, and thinking and non-thinking IC.

The three methods are integrated to construct a comprehensive ICM framework that enables organizations to systematically identify, prioritize, and select KSFs and KPIs as well as strategic and IC-related APs and to simultaneously address critical issues found in past ICM methods. As per the case study results presented in the previous section, the importance of IC-related aspects differs across all considered levels-KSF, KPI, and AP. Furthermore, when the weights and priorities of KSF, KPI, and AP were considered with respect to the IC categories, as Table 8 illustrates, it became clear that although the weights of the IC dimensions differ across the considered levels, most of their rankings are similar; in particular, the priorities of the KSF and KPI levels are identical. As Table 8 demonstrates, all levels adopt a similar focus on the organization dimension and structural capital. On each level, they significantly hold the highest weight of importance and the greatest overall proportion of IC weights. The organization dimension weights are $0.757819,0.8269097$, and 0.7509388 for the KSF, KPI, and AP levels, respectively.

The results presented above indicate that the most significant IC of this focused business unit is the structural capital and that it originates significantly from the organization capital. This finding corroborates several outcomes of previous related studies that highlighted the significant and positive effect of structural capital on corporate performance 
in the manufacturing industry $[42,43]$. Nevertheless, other findings are inconsistent with those of earlier studies. For instance, several studies have documented that IC capitals such as human capital $[44,45]$ and relational capital $[45,46]$ significantly affected firms' performance in the manufacturing industry to a greater extent than structural capital. However, these inconsistent findings suggest that the compared studies had some conflicting or different aspects, such as rough classification of IC components and dimensions, neglect of relationships between IC elements, and differences in the IC levels considered.

Table 8. Weights of IC dimensions in different levels.

\begin{tabular}{llccc}
\hline \multirow{2}{*}{ IC Major Components } & \multirow{2}{*}{ IC Dimensions } & \multicolumn{3}{c}{ Weights of IC Dimensions (Priorities) } \\
\cline { 3 - 5 } & & KSF Level & KPI Level & AP Level \\
\hline \multirow{2}{*}{ Human capital } & Competence & $0.044556(4 \mathrm{th})$ & 0.0318447 (4th) & 0.0163857 (5th) \\
& Attitude & $0.080446(2 \mathrm{nd})$ & 0.0574957 (2nd) & $0.0295844(4 \mathrm{th})$ \\
\hline \multirow{3}{*}{ Structural capital } & Organization & $0.757819(1 \mathrm{st})$ & $0.8269097(1 \mathrm{st})$ & $0.7509388(1 \mathrm{st})$ \\
& Relationship & $0.044556(5 \mathrm{th})$ & 0.0318447 (5th) & $0.1526884(2 \mathrm{nd})$ \\
& Renewal and & $0.072624(3 \mathrm{rd})$ & 0.0519052 (3rd) & 0.0504027 (3rd) \\
\hline
\end{tabular}

As mentioned previously, the case study of the food factory presented and discussed above mainly aims to exemplify the details and results of implementation. To better perceive strengths and weaknesses, the proposed method was also applied to another business unit of THHC - an organic and non-organic farm. Owing to space limitations and the detailed example clearly presented in the first case above, the details of the second implementation are excluded from this paper. Only the quality of the proposed method perceived from the implementation will be considered and discussed. Regarding two cases of implementation, the proposed method shows its dynamic capability. This method can be applied to support executives in managing varied KSFs, KPIs, and strategic plans in different businesses' or situations' strategic and ICM requirements. Although this capability is general and similar to other ICM methods, other different capabilities of the proposed method could contribute to the ICM field. These improvements can be concluded in two major points.

First, in accordance with the integration of ANP, part of the proposed method follows a systematic ANP procedure. Therefore, this adoption could support executives in systematically and logically identifying the priorities and importance weights of IC-related aspects or KSFs by continuing to consider their relationships. The results of the importance weights were also checked for robustness in accordance with the ANP procedure. This can support the reliability of the results obtained from the executive decisions. As Table 3 illustrates, the adoption of the ANP method can provide the weights of importance and priorities of IC aspects. Not only can the concentration of specific KSFs be realized, but the weights of IC groups can also be calculated and are presented in Table 4 . These obtained results can support executives' awareness of the significance of both specific IC sub-elements and major IC components. They also support the management in better understanding and focusing on the identification of KPIs as well as the resources that are significant to the business concept and strategy of the organization. This capability is similarly identified by earlier work in both IC and other managerial fields. However, as mentioned above, existing improved approaches continue to rely primarily on the BSC concept [14,32,33]. Moreover, when compared to other IC-related methods, although BSC can consider relationships among IC-related aspects, which are strategic objectives, it is still unable to identify and prioritize the impacts of IC aspects, while both the process model of IC and the integrated approach of ICM could only support executives to indicate the list of IC aspects without the consideration of relationship and priority. Therefore, the integration of ANP with the proposed method can overcome the flaw found in existing ICM methods.

Second, the combination of the QFD concept with the proposed framework improves the mismatches between strategic focuses and KPIs and between KPIs and strategic APs, 
which are generally created from the unsystematic or unclear identification process. The two-stage analysis of QFD (QFD-I and QFD-II) provides a systematic procedure for aligning relationships and assessing the impacts of associated IC-related aspects in various dimensions-both intra-relationships (among KPIs and among APs) and inter-relationships (between KSFs and KPIs as well as between KPIs and APs). This can support executives' logical and systematic thought processes. Therefore, the integration of QFD can improve existing ICM approaches' unclear processes, which mainly rely on executives' intuition. This improved method provides a robust approach that can be used with any case for ICM. Moreover, regarding QFD's basic ability, the method can calculate final outputs as decimal numbers, which may be further applied to aggregate overall values or total values of specific groups as a means of assessing their impacts. Overall, the integration of QFD may similarly provide the advantages identified in earlier related studies [15]. Nevertheless, as mentioned above, the proposed method offers improved consideration of more comprehensive ranges of IC dimensions than earlier approaches, which focused on rough dimensions of IC with respect to the BSC concept [15].

Based on the contributions identified above, this study mainly offers practical benefits. It improves the ICM approach, making it more extensive and reliable in comparison to traditional ICM methods and their improved forms. The proposed method provides a systematic and detailed procedure that could reduce top management's dependence on experience and intuition. For example, based on the case studies, the MD could improve the IC of the organization by following the ANP and QFD methods; the levels of relationships and the priorities of IC-related aspects were identified following the predefined criteria and calculated according to the methods' equations, respectively. These explicit protocols and guidelines of methods could reduce the decisions that generally rely on the experience and intuition of top management. Therefore, regarding the advantages of the proposed approach, practitioners and scholars may identify and select high-priority IC aspects, such as KSFs, KPIs, and IC-related activities. This result suggests that executives may more efficiently and effectively allocate organizations' limited resources to the critical IC-related aspects identified.

As mentioned above, from a conceptual perspective, the proposed method can address several basic weaknesses of existing ICM approaches. Nevertheless, the application of this complex integrated method requires more processes, resources, and participations than traditional ICM methods. Therefore, to perceive the quality of the proposed method from a practical perspective, feedback from executives representing two cases of THHC for which the proposed method was successfully implemented was analyzed to reveal three major issues. First, the application of ANP requires executives or decision makers who understand and are able to perform complex calculations following the ANP method. An organization without an experienced decision maker may not successfully apply the ANP and also the whole proposed method. This issue conforms to findings in past studies that integrated this MCDM method into other domains [47]. However, currently, several software programs can be used to solve this problem.

Second, the adoption of both ANP and QFD requires more time and the executives' participation since several calculations and decision processes from these two concepts are integrated into the ICM method. Feedback from the focus company's MD indicated that two cases implemented in this study slightly increased participation times as well as executive resources in the strategic planning task owing to the small size of the business units. However, the executive acknowledged that companies or business units in other situations are larger, which would consume more resources and participants' time, because, to comprehensively consider all various strategic functions of organizations, the applications of both QFD-I and QFD-II require diverse executives' opinions. Therefore, to indicate comprehensive sets of KSFs as well as KPIs, and both inter- and intra-correlations, participants from various departments or units should participate in the meeting. However, high participant numbers can lead to extensive debates and be more time-consuming, and this may encroach on executives' working times and possibly affect the quality of their 
work. Therefore, to balance participation times and the quality of executives' opinions, focus groups' sizes must be carefully considered. These cautions with respect to diverse opinions and the appropriately sized focus group also conform to the recommendations identified in an earlier well-known ICM study [6].

Third, regarding the proposed method, more analysis and calculations are necessary than for existing ICM methods. Therefore, these may increase the possibility of incorrect calculations, erroneous analysis, and data input mistakes, which may lead to poor output quality. From the focused cases in this study, several processes performed by the MD were cross-checked by the researcher, and some mistakes were identified. The errors were mainly caused by the unfamiliarity of several newly applied processes. For example, the case studies indicate that although computer software could prevent incorrect calculations, the process for checking decision consistency of decisions was still overlooked by the MD. Therefore, to avoid errors that may have originated from the users' lack of familiarity, work procedure instructions and manuals, checklists for tasks and data collection, and data analysis forms should be provided to inexperienced participants.

\section{Conclusions}

In the past, the availability of ICM methods capable of providing a systematic framework for managing and measuring organizations' strategic IC has been limited. However, these methods still have weaknesses that could not properly manage some fundamental characteristics of IC. Therefore, this study proposes a novel hybrid approach that integrates two different approaches-those of MCDM and the quality improvement method-with the traditional ICM method. This proposed approach aims to address past deficiencies by including decision science methods along with unscientific managerial practice. From this improved concept, this study combines and integrates three different methods-ANP, QFD, and the process model of IC. Thence, this integrated approach was applied to the real case study of two business units of a small enterprise in Thailand. In the case of the food factory, nine KSFs of IC were identified by the company's executive and then prioritized using the ANP method. The first two priorities of KSFs obtained from this process were categorized as organizational capital. The focus on this IC dimension is similar to that of earlier work in other domains. After this process, the QFD technique was applied to identify correlations and to calculate the weights of both KPIs and APs. The outputs from two houses following the QFD concept similarly highlight the focus on IC aspects relating to organizational capital, as identified at the KSF level and in other studies. The implementation of the proposed method, despite its newly integrated approach, remains hindered by several limitations. Based on the implementation of this proposed method at two of the focus company's business units, three major suggestions emerged as follows:

First, although the proposed method may solve several of the critical flaws observed in existing approaches, its advantages are still compensated for by the different theoretical weaknesses, which is the complexity of the method. This weak point leads to greater resource and time consumption. Nevertheless, the adoption of software applications may support firms in addressing this issue in some operations. For example, the QFD software template (based on Microsoft Excel) and Super Decision could facilitate executives and help them to semi-automatically conduct QFD and ANP, respectively. However, other additional processes, such as the pairwise comparison process of ANP and the correlation identification of QFD, which increase the time and resource consumption of firms, are still unavoidable.

Second, to maximize the proposed method's benefits, executives and decision makers should possess the necessary knowledge and skills to implement all methods-ANP, QFD, and the process model of IC-which are integrated together with the proposed ICM approach. Practitioners' high competence may help prevent frequent errors, which are mainly associated with unfamiliarity.

Third, the improved approach proposed herein was mainly developed from a theoretical perspective. Therefore, to investigate its quality, the method was applied to two case studies 
in one specific company. This limits our ability to accurately perceive the method's strengths and weaknesses. Therefore, in the future, to more fully recognize the method's advantages and disadvantages, particularly from a practical perspective, the method should be further implemented in various industries and companies of diverse sizes. Moreover, to identify which ICM methods are most appropriate for a real-world application, a comparative study of both traditional and improved ICM methods is recommended.

In conclusion, this study proposes a new integrated method for ICM that improves on several deficiencies of existing methods. To assess the quality of the proposed method, practical applications were implemented with real cases. Although the method resolves several of the basic weaknesses of existing methods, it nonetheless contains other weaknesses. Therefore, to optimize firms' advantages, executives should prudently consider which specific ICM method is most suitable for their situations.

Author Contributions: Conceptualization, R.W. and D.P.; methodology, R.W. and D.P.; formal analysis, R.W. and D.P.; investigation, R.W. and D.P.; resources, R.W. and D.P.; writing—original draft preparation, R.W.; writing-review and editing, R.W. and D.P.; visualization, R.W. and D.P.; project administration, R.W. and D.P.; funding acquisition, R.W. All authors have read and agreed to the published version of the manuscript.

Funding: This research was funded by TSRI and Chiang Mai University.

Institutional Review Board Statement: This study was conducted in accordance with the Declaration of Helsinki, the International Conference in Harmonization in Good Clinical Practice (ICH-GCP), and the Belmont Report, and the research protocol was approved by the Chiang Mai University Research Ethics Committee on 10 September 2020 (CMUREC No. 63/171 and COE No. 033/63).

Informed Consent Statement: Not applicable.

Data Availability Statement: Not applicable.

Acknowledgments: The authors are immensely thankful for the contributions of the MD of THHC, who sacrificed time and resources to participate in this study.

Conflicts of Interest: The authors declare no conflict of interest.

\section{References}

1. Hayton, J. Competing in the new economy: The effect of intellectual capital on corporate entrepreneurship in high-technology new ventures. RD Manag. 2005, 35, 137-155. [CrossRef]

2. Pedro, E.; Leitão, J.; Alves, H. Back to the future of intellectual capital research: A systematic literature review. Manag. Decis. 2018, 56, 2502-2583. [CrossRef]

3. Lentjušenkova, O.; Lapina, I. An integrated process-based approach to intellectual capital management. Bus. Proc. Manag. 2020, 26, 1833-1850. [CrossRef]

4. Edvinsson, L.; Malone, M. Intellectual Capital: Realizing Your Company's True Value by Finding Its Hidden Brainpower; Harper Business: New York, NY, USA, 1997.

5. Kaplan, R.; Norton, D. The balanced scorecard: Measures that drive performance. Harvard Bus. Rev. 1992, 70, 71-79.

6. Roos, J.; Roos, G.; Dragonetti, N.; Edvinsson, L. Intellectual Capital: Navigating in the New Business Landscape; New York University Press: New York, NY, USA, 1997.

7. Sveiby, K. The New Organizational Wealth: Managing and Measuring Knowledge-Based Assets; Barrett-Kohler: San Francisco, CA, USA, 1997.

8. Bontis, N. National Intellectual Capital Index: A United Nations initiative for the Arab region. J. Intellect. Cap. 2004, 5, 13-39. [CrossRef]

9. Chen, J.; Zhu, Z.; Xie, H.Y. Measuring intellectual capital: A new model and empirical study. J. Intellect. Cap. 2004, 5, 195-212. [CrossRef]

10. Andriesson, D. Implementing the KPMG Value Explorer: Critical success factors for applying IC measurement tools. J. Intellect. Cap. 2005, 6, 474-488. [CrossRef]

11. Kim, D.; Kumar, V. A framework for prioritization of intellectual capital indicators in R\&D. J. Intellect. Cap. 2009, 10, $277-293$.

12. Koo, L.; Koo, H. Holistic approach for diagnosing, prioritising, implementing and monitoring effective strategies through synergetic fusion of SWOT, Balanced Scorecard and QFD. World Rev. Entrep. Manag. Sustain. Dev. 2007, 3, 62-78. [CrossRef]

13. Ghasemzadeh, F.; Pishdar, M.; Antucheviciene, J. Prioritization of petroleum supply chains' disruption management strategies using combined framework of BSC approach, fuzzy AHP and fuzzy Choquet integral operator. J. Bus. Econ. Manag. 2017, 18, 897-919. [CrossRef] 
14. Modak, M.; Pathak, K.; Ghosh, K. Performance evaluation of outsourcing decision using a BSC and Fuzzy AHP approach: A case of the Indian coal mining organization. Resour. Policy 2017, 52, 181-191. [CrossRef]

15. Tavana, M.; Mousavi, N.; Golara, S. A fuzzy-QFD approach to balanced scorecard using an analytic network process. Int. J. Inf. Decis. Sci. 2013, 5, 331-363. [CrossRef]

16. Golrizgashti, S.; Shanehsaz, N. A Proposed Approach to Link Between Strategy and Customer's Requirements. Int. J. Manag. App. Sci. 2018, 4, 69-71.

17. Wudhikarn, R.; Chakpitak, N.; Neubert, G. A literature review on performance measures of logistics management: An intellectual capital perspective. Int. J. Prod. Res. 2018, 56, 4490-4520. [CrossRef]

18. Wu, Y.; Chou, Y. A new look at logistics business performance: Intellectual capital perspective. Int. J. Logist. Manag. 2007, 18, 41-63.

19. Bhagwat, R.; Sharma, M. An application of the integrated AHP-PGP model for performance measurement of supply chain management. Prod. Plan. Control 2009, 20, 678-690. [CrossRef]

20. Hudson, M.; Smart, A.; Bourne, M. Theory and practice in SME performance measurement systems. Int. J. Oper. Prod. Manag. 2001, 21, 1096-1115. [CrossRef]

21. Lee, S. Using fuzzy AHP to develop intellectual capital evaluation model for assessing their performance contribution in a university. Expert Syst. Appl. 2010, 37, 4941-4947. [CrossRef]

22. Calabrese, A.; Costa, R.; Menichini, T. Using Fuzzy AHP to manage Intellectual Capital assets: An application to the ICT service industry. Expert Syst. Appl. 2013, 40, 3747-3755. [CrossRef]

23. Nedjati, A.; Izbirak, G. Evaluating the Intellectual Capital by ANP Method in a Dairy Company. Procedia Soc. Behav. Sci. 2013, 107, 136-144. [CrossRef]

24. Jiang, D.; Liu, Z. Research on Application of Balanced Scorecard in the Government Performance Appraisal. Open J. Soc. Sci. 2014, 2, 91-96. [CrossRef]

25. Wudhikarn, R. An efficient resource allocation in strategic management using a novel hybrid method. Manag. Decis. 2016, 54, 1702-1731. [CrossRef]

26. Tan, B.; Tang, N.; Forrester, P. Application of QFD for e-Business planning. Prod. Plan. Control 2004, 15, 802-818. [CrossRef]

27. Akao, Y. Quality Function Deployment: Integrating Customer Requirements into Product Design; Productivity Press: Cambridge, MA, USA, 1990.

28. Hauser, J.; Clausing, D. The House of Quality. Harvard Bus. Rev. 1988, 66, 63-73.

29. Han, D.; Han, I. Prioritization and selection of intellectual capital measurement indicators using analytic hierarchy process for the mobile telecommunications industry. Expert Syst. Appl. 2004, 26, 519-527. [CrossRef]

30. Liu, C. Developing green intellectual capital in companies by AHP. In Proceedings of the 8th International Conference on Supply Chain Management and Information, Hong Kong, China, 6-9 October 2010; Choy, K.L., Chan, F.T.S., Ho, G., Eds.; The Hong Kong Polytechnic University: Hong Kong, China, 2010.

31. Saaty, T. The Analytic Network Process; RWS Publications: Pittsburgh, PA, USA, 1996.

32. Marcarelli, G. An integrated network model for performance management: A focus on healthcare organisations. Int. J. Manag. Financ. Account. 2018, 10, 163-180.

33. Kucukaltan, B.; Irani, Z.; Aktas, E. A decision support model for identification and prioritization of key performance indicators in the logistics industry. Comput. Hum. Behav. 2016, 65, 346-358. [CrossRef]

34. Murali, S.; Pugazhendhi, S. An integrated model to identify and rank the after sales service strategies of firms engaged in household appliances business. Int. J. Serv. Oper. Manag. 2016, 24, 246-267. [CrossRef]

35. Hsu, C.; Chang, A.; Luo, W. Identifying key performance factors for sustainability development of SMEs-Integrating QFD and fuzzy MADM methods. J. Clean. Prod. 2017, 161, 629-645. [CrossRef]

36. Lin, Y.; Cheng, H.; Tseng, M.; Tsai, J. Using QFD and ANP to analyze the environmental production requirements in linguistic preferences. Expert Syst. Appl. 2010, 37, 2186-2196. [CrossRef]

37. Mubarik, M.; Chandran, V.; Devadason, E. Measuring Human Capital in Small and Medium Manufacturing Enterprises: What Matters? Soc. Indic. Res. 2018, 137, 605-623. [CrossRef]

38. Petty, R.; Guthrie, J. Intellectual capital literature review: Measurement, reporting and management. J. Intellect. Cap. 2000, 1 , 155-176. [CrossRef]

39. Saaty, T. Decision making-The analytic hierarchy and network processes (AHP/ANP). J. Syst. Sci. Syst. Eng. 2004, 1, 1-35. [CrossRef]

40. Badawy, M.; El-Aziz, A.; Idress, A.; Hefny, H.; Hossam, S. A survey on exploring key performance indicators. Future Comput. Inform. J. 2016, 1, 47-52. [CrossRef]

41. Parmenter, D. Key Performance Indicators: Developing, Implementing, and Using Winning KPIs; John Wiley \& Sons, Inc.: Hoboken, NJ, USA, 2015.

42. Xu, J.; Liu, F. The Impact of Intellectual Capital on Firm Performance: A Modified and Extended VAIC Model. J. Compet. 2020, 12, 161-176. [CrossRef]

43. $\mathrm{Xu}, \mathrm{J} . ; \mathrm{Li}, \mathrm{J}$. The interrelationship between intellectual capital and firm performance: Evidence from China's manufacturing sector. J. Intellect. Cap. 2020. Epub ahead of printing. [CrossRef] 
44. Phusavat, K.; Comepa, N.; Sitko-Lutek, A.; Ooi, K. Interrelationships between intellectual capital and performance: Empirical examination. Ind. Manag. Data Syst. 2011, 111, 810-829. [CrossRef]

45. Xu, J.; Wang, B. Intellectual Capital, Financial Performance and Companies' Sustainable Growth: Evidence from the Korean Manufacturing Industry. Sustainability 2018, 10, 4651. [CrossRef]

46. Chen, Y.; Lin, M.; Chang, C. The Influence of Intellectual Capital on New Product Development Performance-The Manufacturing Companies of Taiwan as an Example. Total Qual. Manag. Bus. Excell. 2006, 17, 1323-1339. [CrossRef]

47. Sharma, S.; Mahapatra, S.; Parappagoudar, M. Benchmarking of product recovery alternatives in reverse logistics. Benchmarking Int. J. 2016, 23, 406-424. [CrossRef] 